NOTES

\title{
Interphase Migration of a Hindered Phenol Compound in Acrylate Rubber/Chlorinated Polypropylene Blends
}

\author{
Chifei $\mathrm{WU}^{\dagger}$ \\ Institute of Material Science and Technology, East China University of Science and Technology, \\ 130 Meilong-lu, Shanghai 200237, China
}

(Received November 20, 2002; Accepted December 25, 2002) KEY WORDS Acrylate Rubber / Chlorinated Polypropylene / Hindered Phenol / Dynamic Mechan-
ical Property / Interphase Migration / Damping /

In recent studies, ${ }^{1,2}$ our attention has been focused on the discovery of unknown functions of a polymer elicited by the addition of small molecular substances. It was found that the addition of 3,9-bis $\{1,1-$ dimethyl-2[ $\beta$-(3-tert-butyl-4-hydroxy-5-methylphenyl) propionyloxy]ethyl $\}$-2,4,8,10-tetraoxaspiro[5,5]-undecane (AO-80) into an immiscible acrylate rubber (ACM) and chlorinated polypropylene (CPP) blend not only resulted in a remarkable enhancement of the damping properties but also gave the $\mathrm{ACM} / \mathrm{CPP}$ blend significant peel strength. As a result, a ternary blend of $\mathrm{ACM} / \mathrm{CPP}$ with more $\mathrm{AO}-80$ was found to be a very good self-adhesive damping material. It has also been revealed that the AO- 80 molecules are preferentially distributed to a continuous ACM phase when the AO- 80 content is lower than $30 \%$. In order to obtain a very broad, almost rectangular transition range with values for the area under the linear loss factor $(\tan \delta)$ curve, it is important to control AO-80 distribution in each phase of an immiscible ACM/CPP blend because polymer blends with organic small molecule substance prepared by different methods could show differences in damping properties. ${ }^{3}$

On the other hand, much interest has been shown in diffusion and transport of organic small molecules within polymer blends. ${ }^{4,5}$ In addition the technological importance of the molecular transport of organic small molecules within polymer blends plays a vital role in a variety of applications such as separation processes, ${ }^{6}$ controlled drug release, ${ }^{7}$ reverse osmosis, ${ }^{8}$ and microelectronics. ${ }^{9}$ It has been pointed out that the primary goal of these studies was to estimate the sorption, diffusion, and permeation coefficients and to study their temperature dependence. However, a survey of the literature revealed that the mechanism by which the trans- port of organic small molecule influences the dynamic mechanical properties of a polymer blend has not been studied thoroughly.

The aim of the present study is to establish a method for controlling the dynamic mechanical properties of an immiscible ACM/CPP blend with AO-80 by the transport of AO-80 molecules from CPP domains to the $\mathrm{ACM}$ matrix during heat treatment at a temperature above the melting point of AO-80. For this purpose, unpressed samples of $\mathrm{ACM} / \mathrm{CPP}$ with $\mathrm{AO}-80$ sample in which AO-80 as crystalline particles are preferentially distributed in the CPP phase were prepared. Another aim of this study was to try establishing a new concept for designing a damping material with a broad, almost rectangular loss tangent $\tan \delta$ peak.

\section{EXPERIMENTAL}

The ACM used in this study was commercial grade (Nippon zeon Co., Nipol AR42 W); CPP with 29.5\% of the weight content of chloride was a thermoplastic resin (Nippon paper industries Co., Superchlon 803MWS). The AO-80 (as shown in Figure 1 of ref 1) used as a functional additive, was a commercial antioxidant (ADK STAB AO-80; Asahi Denka Industries Co.). The melting point of AO- 80 is $123^{\circ} \mathrm{C}$ as determined by differential scanning calorimetry. The AO- 80 and CPP were firstly kneaded by mixing rollers for $10 \mathrm{~min}$ at $90^{\circ} \mathrm{C}$ and then the kneaded AO-80/CPP mixture was added to ACM at $50^{\circ} \mathrm{C}$. The kneaded ACM/CPP/AO$80(7 / 3 / 3)$ sample was pressed in a laboratory hot press at $80^{\circ} \mathrm{C}$ for $5 \mathrm{~min}$ under a pressure of $20 \mathrm{MPa}$. This pressed sheet, in which the CPP domain sizes were about $30 \mu \mathrm{m}$ in length and $6 \mu \mathrm{m}$ in width, ${ }^{1}$ was directly cut into rectangular pieces for various measurements.

${ }^{\dagger}$ To whom correspondence should be addressed (Tel: +86-21-64252569, Fax: +86-21-64252569, E-mail: wucf@ecust.edu.cn). 


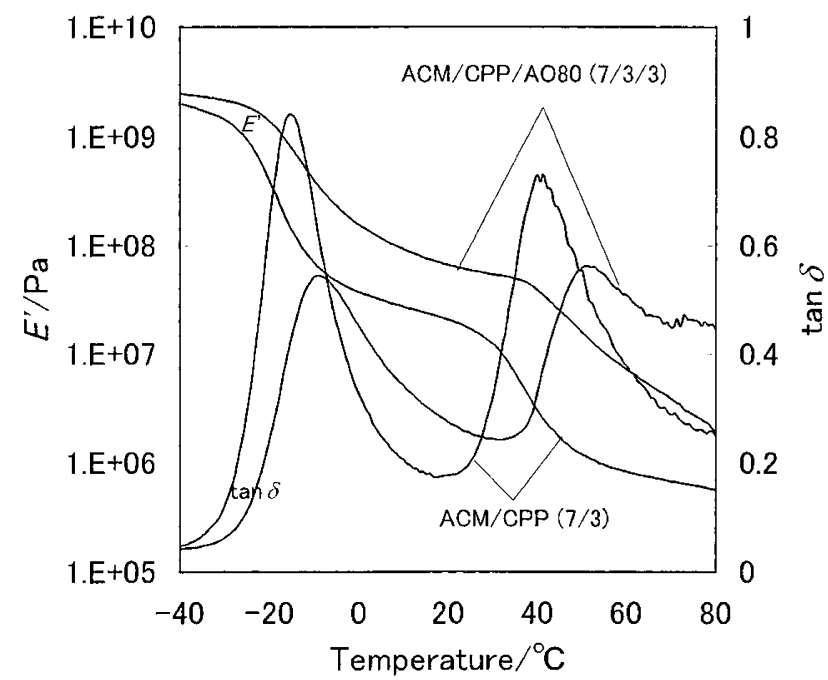

Figure 1. Temperature dependence of $E^{\prime}$ and $\tan \delta$ of $\mathrm{ACM} / \mathrm{CPP}(7 / 3)$ blend and ACM/CPP/AO-80 (7/3/3) blend.

Moreover, this sheet in which the crystalline particles of AO- 80 were distributed in CPP domains was placed in a constant temperature chamber at 130 (and $160^{\circ} \mathrm{C}$ ). And then quenched in an ice-water bath for the transport of AO-80 molecules from CPP domains to ACM matrix.

The dynamic mechanical measurements were carried out using a dynamic mechanical analyzer (Rheology Co., DVE-V4) on sample specimens of the following dimensions: $20 \mathrm{~mm}$ long, $5 \mathrm{~mm}$ wide, and $1 \mathrm{~mm}$ thick. The temperature dependence of dynamic tensile moduli was measured at a constant frequency of $11 \mathrm{~Hz}$ and at a heating rate of $3^{\circ} \mathrm{C} \mathrm{min}-1$.

\section{RESULTS AND DISCUSSION}

The additive effects of AO- 80 crystalline particles on the temperature dependencies of storage modulus $E^{\prime}$ and $\operatorname{tangent} \tan \delta$ of a polymer blend of ACM and CPP (7:3) are shown in Figure 1. As shown in figure, an $\mathrm{ACM} / \mathrm{CPP}$ blend exhibits two significant transitions, indicating that an $\mathrm{ACM} / \mathrm{CPP}$ blend is immiscible. These two transitions are attributed to glass transitions of ACM and CPP, respectively. The total effect of the added AO- 80 crystalline particles is a broadening of the glass transition and an increases in $E$. It was also found that the rise in the glass transition temperature of CPP is greater than that of $\mathrm{ACM}$, indicating that AO-80 in untreated ACM/CPP/AO- 80 sample has been preferentially distributed in the CPP phase in the form of crystalline particles.

To determine the optimal heat treatment conditions, the influences of heat treatment temperature on the dynamic mechanical properties of ACM/CPPAO- 80 (7:3:3) were studied. The temperature dependencies of

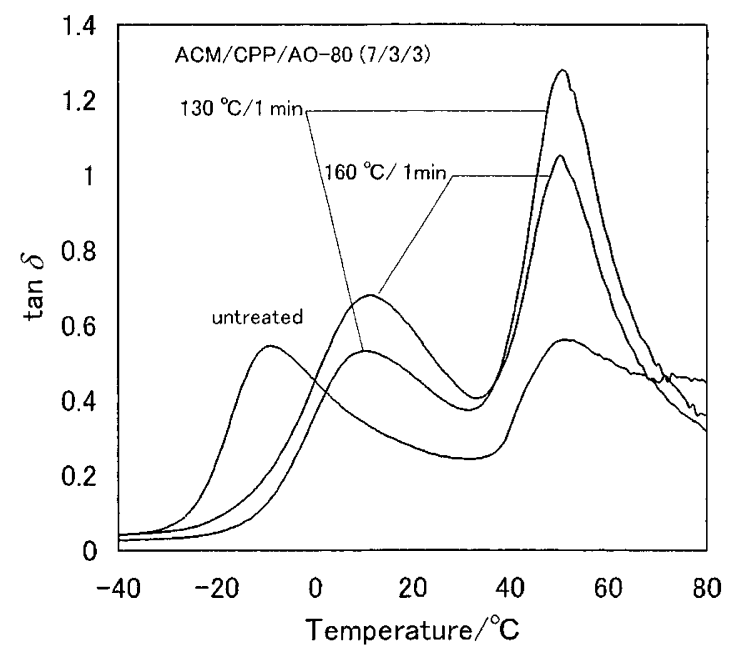

Figure 2. The effects of heat treatment on the temperature dependence of $\tan \delta$ of an ACM/CPP/AO-80 (7/3/3) blend.

$\tan \delta$ of an ACM/CPPAO- 80 blend and its heat-treated samples are presented in Figure 2. A sample heattreated at $160^{\circ} \mathrm{C}$ for $1 \mathrm{~min}$ exhibited both an increase in the $\tan \delta$ value and a rise in the first $\tan \delta$ peak temperature due to ACM. The results of our previous works ${ }^{1,10}$ on the additive effects of AO- 80 on various polar polymers such as acrylic rubber, styrene butadiene rubber, nitril butadiene rubber, polyvinyl acetate, and chlorinated polypropylene showed that the maximum $\tan \delta$ peaks of those systems were drastically increased by the addition of AO-80. Therefore, a drastic increase in the second peak is thought to be due to the effect of AO-80 dissolved to the CPP phase. In contrast, an increase and shift in the first peak was also clearly observed. Similarly, this change is due to the addition of AO-80 in ACM. This finding suggests that some of the AO-80 molecules are transported from CPP domains to the ACM matrix during heat treatment at $160^{\circ} \mathrm{C}$ for $1 \mathrm{~min}$. This is possible because the intermolecular interaction of AO-80 with ACM is greater than that with $\mathrm{CPP}$, as demonstrated by the results of analysis of the dynamic mechanical properties and infrared spectra of binary blends with AO-80. ${ }^{1}$ In order to obtain a full picture of migration of AO- 80 molecules in an ACM/CPP blend, heat treatment at lower temperature is needed. As can be seen in Figure 2, for a sample treated at $130^{\circ} \mathrm{C}$ for $1 \mathrm{~min}$, the second peak was higher and the first peak was lower than the peaks in the case of an untreated ACM/CPP sample. In addition a shift in the first peak was also smaller than that of a sample treated at $160^{\circ} \mathrm{C}$ for $1 \mathrm{~min}$. This implies that there was little migration of AO- 80 molecules in an ACM/CPP blend during heat treatment at $130^{\circ} \mathrm{C}$ for $1 \mathrm{~min}$. Consequently, we used $130^{\circ} \mathrm{C}$ as the heat treatment temperature in this study.

Figure 3 shows the effects of heat treatment at $130^{\circ} \mathrm{C}$ 


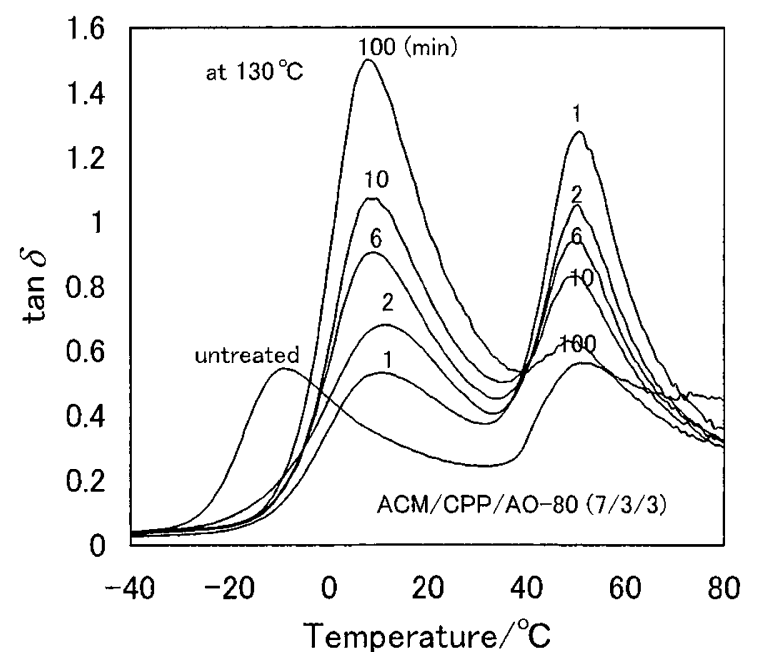

Figure 3. Temperature dependence of $\tan \delta$ of ACM/CPP/AO$80(7 / 3 / 3)$ blend heat-treated at $130{ }^{\circ} \mathrm{C}$ for various times. The numbers shown in the figure are heat treatment time (min).

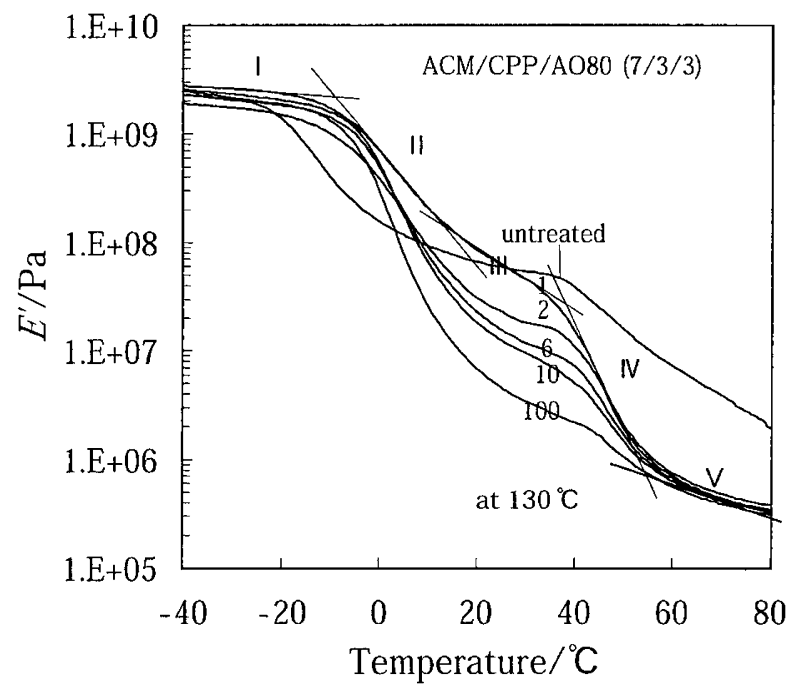

Figure 4. Temperature dependence of $E^{\prime}$ of ACM/CPP/AO-80 $(7 / 3 / 3)$ blend heat-treated at $130{ }^{\circ} \mathrm{C}$ for various times. The numbers shown in the figure are heat treatment time ( $\mathrm{min})$.

on the temperature dependence of $\tan \delta$. As shown in figure, the second peak monotonously decreases and the first peak conversely increases as the heat treatment time is increased. This change is associated with the transport of AO- 80 molecules from the CPP domains to the ACM matrix during the heat treatment process. When the heat treatment time was extended to $100 \mathrm{~min}$, the second peak was close to that of an untreated sample. Therefore, it is thought that most of the AO- 80 molecules migrate into the ACM phase when the sample is heat-treated for $100 \mathrm{~min}$.

There are five distinct domains on the $E^{\prime}$ curve shown in Figure 4: two dispersion regions (II and IV) in which $E^{\prime}$ changes rapidly with temperature, as well as three regions (I, III, and V) that show a much more gentle decrease in slope, resembling the behavior in the region of a plateau. It was found that with an increase in heat treatment time the relaxation strength of the second dispersion decreases, whereas that of the first peak conversely increases. An increase in the strength of relaxation due to ACM and decrease in the strength of relaxation due to CPP are also attributed to the migration of AO- 80 molecules from the CPP domains to the ACM matrix. Thus, the transport behavior of AO- 80 molecules distributed in an ACM/CPP blend can be described by changes in $\tan \delta$ and $E^{\prime}$.

In addition, a comparison of the relaxation strength (Figure 4) and the height of the $\tan \delta$ peak (Figure 3) showed that the height of the $\tan \delta$ peak is proportional to the relaxation strength. This is consistent with the relationship found in another binary system of chlorinated polyethylene and chlorinated paraffin. ${ }^{3}$

Control of temperature dependence of $\tan \delta$ of a given material is of crucial importance in many applications such as damping. By its definition, $\tan \delta$ is determined by both $E^{\prime \prime}$ and $E^{\prime}$. While $E^{\prime}$ is a measure of the energy returned to the system, $E^{\prime \prime}$ is $90^{\circ}$ out of phase and is related to the component of lost energy. Therefore, $\tan \delta$ is a ratio of the work converted into heat to that recovered, for a given work input. In general, for outdoor or machinery applications, good damping materials should exhibit a high loss factor $(\tan \delta>0.5)$ over a temperature range of at least $60-80^{\circ} \mathrm{C} .{ }^{11}$ With an increase in the heat treatment time, the second peak decreased and the first peak increased, and these two peaks were the same when heat treatment time was $5 \mathrm{~min}$. In addition, the valley between the two peaks became high. Thus, it was concluded that the temperature dependence of $\tan \delta$ for an ACM/CPP blend with AO-80 can be improved by selection of appropriate heat treatment time. In particular, it is noteworthy that as a result the same performance as that of many interpenetrating polymer networks (IPN) can be obtained. ${ }^{12,13}$ Therefore, this is considered to be a new approach to improving the temperature dependence of $\tan \delta$.

\section{CONCLUSIONS}

The effects of heat treatment at $130^{\circ} \mathrm{C}$ on the dynamic mechanical properties of a blend of ACM and CPP with AO-80 were investigated. An untreated $\mathrm{ACM} / \mathrm{CPP} / \mathrm{AO}-80$ (7/3/3) sample in which AO-80 was mainly distributed as crystalline particles in the CPP domains showed two relaxations. Heat treatment at $130^{\circ} \mathrm{C}$ for $1 \mathrm{~min}$ caused a drastically increase in the $\tan \delta$ peak due to the CPP phase. This is thought to be due to the effect of the addition of AO-80 dissolved in the CPP phase. With further increases in heat treatment time, the first peak drastically increased and the 
second peak monotonously decreased. This change is associated with the transport of AO- 80 molecules from the CPP domains to the ACM matrix during the heat treatment process. Thus, the temperature dependence of $\tan \delta$ for an ACM/CPP blend with AO- 80 can be improved by selecting appropriate heat treatment time.

\section{REFERENCES}

1. C.-F. Wu, Y. Otani, N. Namiki, H. Emi, and K. Nitta, Polym. J., 33, 322 (2001).

2. C.-F. Wu and S. Akiyama, Polym. J., 33, 955 (2001).

3. C.-F. Wu, J. Polym. Sci., Part B: Polym. Phys., 39, 23 (2001).

4. L. A. Errede, Macromolecules, 19, 654 (1986).

5. A. R. Berens and H. B. Hopfenberg, Polymer, 19, 489 (1978).
6. O. M. David, Q. T. Nguyen, and J. Neel, J. Membr. Sci., 73, 129 (1992).

7. N. E. Cooke, J. Polym. Sci., Part B: Polym. Phys., 29, 1633 (1991).

8. S. Sourirajan, Ind. Eng. Chem. Process des. dev., 6, 154 (1967).

9. H. Coll and C. G. Searles, Polymer, 29, 1266 (1988).

10. C.-F. Wu, T. Nomura, T. Mihara, and K. Hashimoto, U. S. Patent 09363749 (July 30, 1999).

11. T. Ogawa, J. Adhes. Soc. Jpn., 34, 263 (1998).

12. R. Hu, V. L. Dimonie, M. S. El-aasser, R. A. Pearson, A. Hiltner, S. G. Mylonakis, L. H. Sperling, and J. Fay, J. Polym. Sci., Part B: Polym. Phys., 35, 1501 (1997).

13. D. J. Hourston, F. U. Schafer, and J. S. Bates, J. Appl. Polym. Sci., 60, 2409 (1994). 